\title{
19
}

\section{Sizing a New CSO Storage Tank using Continuous SWMM}

\section{Mark Stirrup}

The Region of Hamilton-Wentworth completed a Pollution Control Plan (PCP) in 1991 to address pollution from 23 combined sewer overflows (CSOs) which discharged to local receiving waters. The PCP recommended the construction of 10-12 underground storage tanks to intercept and detain CSOs at these outfalls during wet weather, for subsequent conveyance to and treatment by the Woodward Avenue Wastewater Treatment Plant during dry weather. The target CSO frequency from the tanks was 1-4 CSOs per year, and an $87-95 \%$ reduction in previously existing annual CSO volumes. The Region has made significant progress with the implementation of its PCP since 1991. Five CSO storage tanks are in operation. Together these facilities provide approximately $193,000 \mathrm{~m}^{3}$ of additional CSO storage volume. Four tanks have been constructed since the completion of the PCP and were designed to reduce the number of CSOs at nine former outfalls from up to 29/y to 1-3/y (May to October).

Construction of the first tank, a $70,000 \mathrm{~m}^{3}$ facility located at the east end of Greenhill Avenue, was completed in 1988 prior to the completion of the PCP. This tank was designed to retain the runoff from a $15 \mathrm{~mm}$ storm. Storms of this size occur fairly frequently, and as a result, the Greenhill CSO tank typically overflows about 13 times/y (May to October). The Region has decided to construct a second storage tank to improve the level of CSO control at the Greenhill outfall and to meet new provincial CSO control objectives set out in the Ontario Ministry of the Environment's Procedure F-5-5. The sizing of the

Stirrup, M. 2001. "Sizing a New CSO Storage Tank using Continuous SWMM." Journal of Water Management Modeling R207-19. doi: 10.14796/JWMM.R207-19.

(C) CHI 2001 www.chijournal.org ISSN: 2292-6062 (Formerly in Models and applications to Urban Water Systems. ISBN: 0-9683681-4-X) 
tank was done in-house by Regional staff using the USEPA Stormwater Management Model (SWMM) Version 4.0. This chapter will discuss in detail the methodology used to determine the size of the tank required to meet desired CSO control objectives. This methodology is based upon the premise that continuous modeling is the only reliable way to ensure that the tank performs to these control criteria under real operating conditions for long periods of time.

\subsection{Background}

The Region of Hamilton-Wentworth operates and maintains an extensive combined sewer system (CSS). Two large interceptor sewers collect combined sewage from an area of approximately $54 \mathrm{~km}^{2}$ and convey it to the Woodward Avenue Wastewater Treatment Plant (WWTP) in Hamilton's east end (see Figure 19.1). During dry weather and small storm events, all combined sewage is conveyed to the WWTP where it receives treatment before being discharged into the eastern end of Hamilton Harbour. During large storm events, the inflows to the CSS can exceed the capacity of the interceptors and/ or WWTP, and excess flows must be diverted to local receiving waters. The Region's CSS discharges CSOs to Hamilton Harbour, Cootes Paradise, Chedoke Creek and Red Hill Creek at up to 23 locations. These diversions are necessary in order to prevent basement flooding and ensure that the interceptor sewers and Woodward Avenue WWTP are not overloaded. Typically these CSOs occur about 23 times/y (May 1 to October 31), and discharge over 4.3 million $\mathrm{m}^{3}$ of untreated combined sewage to local receiving waters each year during this same period.

The Hamilton Harbour Remedial Action Plan (HHRAP) has identified CSOs as a significant source of pollutants and recommended that the Region undertake specific measures to eliminate or minimize pollution from these discharges (Hamilton Harbour RAP Team, 1992). To address the CSO problem, the Region completed the Hamilton-Wentworth Region Pollution Control Plan (PCP) in 1991. The recommended CSO control strategy relies heavily on off-line storage, with an associated expansion of the Woodward Avenue WWTP to achieve target reductions of CSOs to 1-4/y on average (Paul Theil Associates and Beak Consultants 1991). The PCP recommended the construction of 10-12 CSO storage facilities to detain overflows during periods of wet weather. During dry weather, the stored wastewater is pumped and/or drained back into the sanitary interceptors and conveyed to the Woodward Avenue WWTP for treatment. The PCP also recommended that further improvements can be gained through real time control (RTC) of automatic sluice gates and CSO storage tanks. Estimated total remediation costs ranged 


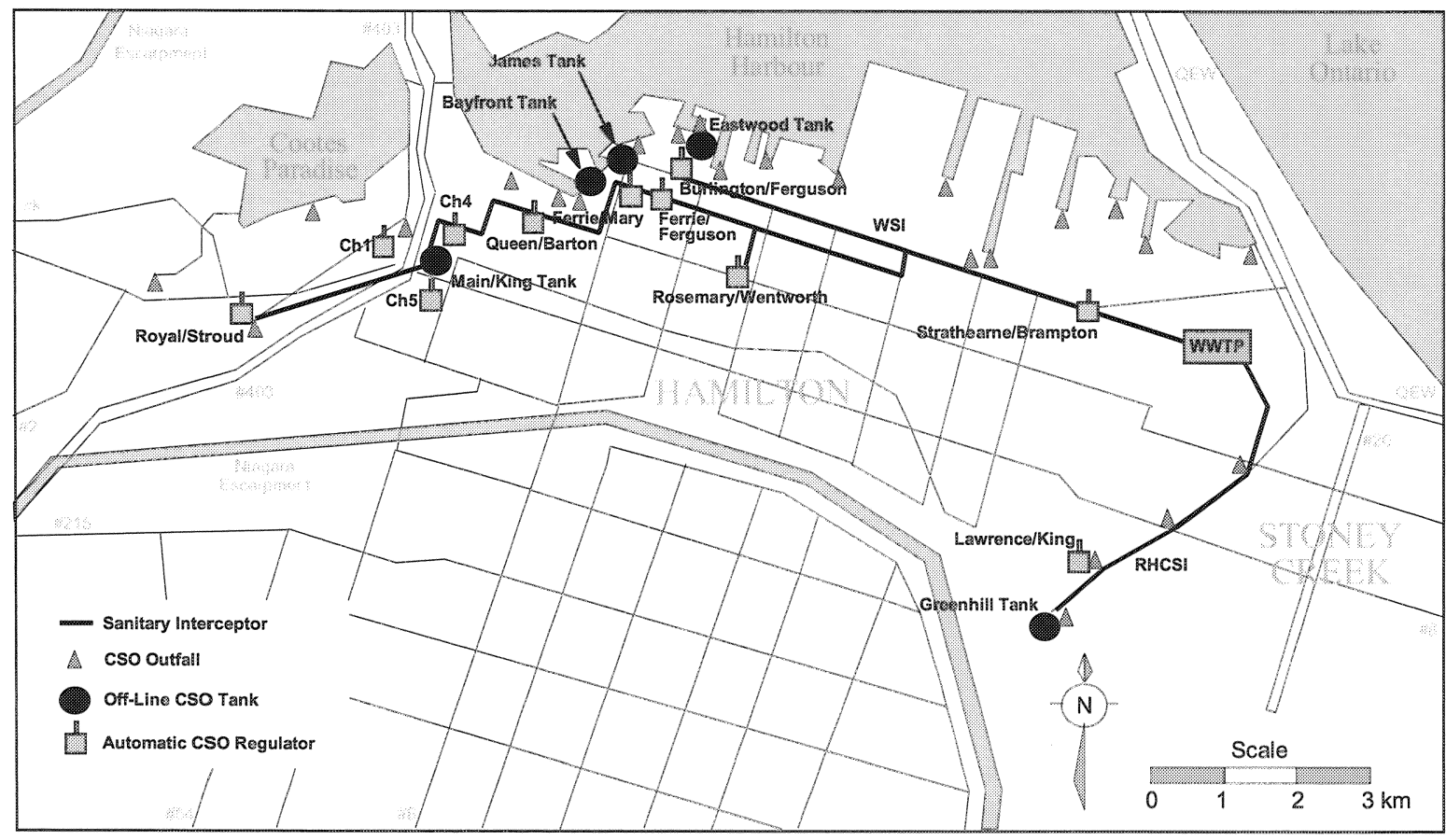

Figure 19.1 Hamilton's combined sewer system. 
from $\$ 186$ million (to achieve four CSOs/y) to $\$ 248$ million (to achieve one $\mathrm{CSO} / \mathrm{y}$ ). The PCP was approved by the Region's Environmental Services Committee in October 1992, and subsequently adopted by Regional Council.

The Region is making significant progress with the implementation of its PCP. Five off-line CSO storage tanks are already in operation. Their locations are indicated in Figure 19.1. Together, these facilities provide approximately $193,000 \mathrm{~m}^{3}$ of additional CSO storage volume, and were constructed at a total cost of $\$ 47$ million. Table 19.1 provides some details about each of these facilities, including design criteria, storage volume required to reach these criteria and costs to construct them. Table 19.2 estimates the performance of our existing CSO control facilities in reducing previous $\mathrm{CSO}$ volumes from each outfall and from the system as a whole. This analysis, carried out for a typical year (1989) using SWMM, indicates that the five existing tanks typically remove approximately $78 \%$ of the CSO volume, which occurred prior to the construction of these facilities.

Construction of the Greenhill CSO Storage Facility was completed in 1988 prior to the completion of the PCP, and as shown in Table 19.2, the level of CSO control provided by this facility is significantly below that of the four facilities constructed since. The Region has decided to construct a second storage tank to improve the level of CSO control at the Greenhill outfall. The sizing of the tank was done in-house by Regional staff using SWMM Version 4.0. The objective of this chapter is to present in detail the methodology used to determine the size of the tank required to meet desired CSO control objectives.

\subsection{CSO Control Targets}

Prior to construction of the four newest CSO tanks, the Region's CSO outfalls were typically active 23 times/y during the period from May to October (Paul Theil Associates and Beak Consultants, 1991). The PCP study recommended controls to reduce the frequency of overflows to one or four CSOs/y (May 1 to October 31), which would reduce existing CSO volumes by $95 \%$ and $87 \%$ respectively. The required sizes of the CSO storage tanks to meet one and four CSOs/yr were identified by single event modeling using SWMM. One and four year design storms were developed by the consultant and the SWMM Runoff and Transport modules were used to estimate the size of each CSO tank required to completely retain the runoff from these storms.

In February 1997, the Ontario Ministry of the Environment (MOE) released Procedure F-5-5, a new procedure for the determination of treatment requirements for municipal and private combined and partially separated sewer systems (MOE, 1997). The goals of this procedure are to eliminate the 
Table 19.1 Existing CSO storage tanks in Hamilton.

\begin{tabular}{|c|c|c|c|c|}
\hline ID & Name \& location & Size & Completion date and cost & CSO design criteria \\
\hline $\mathrm{CSO}-1$ & $\begin{array}{l}\text { Greenhill CSO Tank; located at } \\
\text { the east end of Greenhill Avenue, } \\
\text { on the west side of the Redhill } \\
\text { Creek. }\end{array}$ & Tank Volume $\sim 70,000 \mathrm{~m}^{3}$ & $\begin{array}{l}\text { Completed in } 1988 \text { prior } \\
\text { to adoption of } \mathrm{PCP} \text {, at a } \\
\text { cost of approximately } \$ \\
5.0 \text { million. }\end{array}$ & $\begin{array}{l}\text { Designed to retain } \\
\text { runoff from } 15 \mathrm{~mm} \\
\text { design storm. }\end{array}$ \\
\hline $\mathrm{CSO}-2$ & $\begin{array}{l}\text { Bayfront Park CSO Tank; located } \\
\text { at Hamilton's Bayfront Park, at } \\
\text { the west end of Strachan Street, } \\
\text { south of Simcoe Street. }\end{array}$ & Tank Volume $\sim 20,000 \mathrm{~m}^{3}$ & $\begin{array}{l}\text { Completed in } 1993 \text {, at a } \\
\text { cost of approximately } \\
\$ 9.3 \text { million. }\end{array}$ & $\begin{array}{l}\text { Designed to reduce } \\
\text { frequency of CSOs } \\
\text { at two former } \\
\text { outfalls from } 13 / \mathrm{yr} \\
\text { to } 1 / \mathrm{yr} \text { on average. }\end{array}$ \\
\hline $\mathrm{CSO}-3$ & $\begin{array}{l}\text { James Street CSO Tank; located } \\
\text { at the foot of James Street, north } \\
\text { of Guise Street. }\end{array}$ & $\begin{array}{l}\text { Tank Volume } \sim 1,400 \mathrm{~m}^{3}, \\
\text { with up to } 1,800 \mathrm{~m}^{3} \text { of } \\
\text { additional in-line storage } \\
\text { provided by downstream } \\
\text { sewer. }\end{array}$ & $\begin{array}{l}\text { Completed in } 1993 \text {, at a } \\
\text { cost of approximately } \\
\$ 1.5 \text { million. }\end{array}$ & $\begin{array}{l}\text { Designed to reduce } \\
\text { frequency of CSOs } \\
\text { at a single outfall } \\
\text { from } 24 / \mathrm{yr} \text { to } 1 / \mathrm{yr} \\
\text { on average. }\end{array}$ \\
\hline $\mathrm{CSO}-4$ & $\begin{array}{l}\text { Main/King CSO Tank; located in } \\
\text { Cathedral Park, bounded by Main } \\
\text { Street West, Hwy 403, King } \\
\text { Street West, and Dundurn Street. }\end{array}$ & Tank Volume $\sim 75,000 \mathrm{~m}^{3}$ & $\begin{array}{l}\text { Completed in } 1997 \text {, at a } \\
\text { cost of approximately } \\
\$ 23.0 \text { million. }\end{array}$ & $\begin{array}{l}\text { Designed to reduce } \\
\text { frequency of CSOs } \\
\text { from } 3 \text { former } \\
\text { outfalls from } 29 / \mathrm{yr} \\
\text { to } 2-3 / \mathrm{yr} \text { on } \\
\text { average. }\end{array}$ \\
\hline $\mathrm{CSO}-5$ & $\begin{array}{l}\text { Eastwood Park CSO Tank; } \\
\text { located in Eastwood Park, on the } \\
\text { southwest corner of Ferguson } \\
\text { Avenue and Dock Service Road. }\end{array}$ & Tank Volume $\sim 25,000 \mathrm{~m}^{3}$ & $\begin{array}{l}\text { Completed in } 1997 \text {, at a } \\
\text { cost of approximately } \\
\$ 8.5 \text { million. }\end{array}$ & $\begin{array}{l}\text { Designed to reduce } \\
\text { frequency of CSOs } \\
\text { from two former } \\
\text { outfalls from } 27 / \mathrm{yr} \\
\text { to } 2-3 / \mathrm{yr} \text { on } \\
\text { average. }\end{array}$ \\
\hline
\end{tabular}

Tank Volume $\sim 1,400 \mathrm{~m}^{3}$, with up to $1,800 \mathrm{~m}^{3}$ of additional in-line storage provided by downstream Park, bounded by Main located in Eastwood Park, on the southwest corner of Ferguson Avenue and Dock Service Road. 
Table 19.2 Performance of existing CSO storage tanks in Hamilton.

\begin{tabular}{|c|c|c|c|c|c|c|c|}
\hline CSO Tank & $\begin{array}{l}\text { Contributing } \\
\text { CSO Outfalls }\end{array}$ & $\begin{array}{r}\text { WWF Vol. } \\
\left(\mathrm{m}^{3}\right)\end{array}$ & $\begin{array}{r}\text { CSO Vol. } \\
\text { without } \\
\text { Existing } \\
\text { Tanks } \\
\left(\mathrm{m}^{3}\right)\end{array}$ & $\begin{array}{r}\text { CSO Vol. } \\
\text { with } \\
\text { Existing } \\
\text { Tanks } \\
\left(\mathrm{m}^{3}\right)\end{array}$ & $\begin{array}{r}\text { CSO Vol. } \\
\text { removed by } \\
\text { Existing } \\
\text { Tanks } \\
\left(\mathrm{m}^{3}\right)\end{array}$ & $\begin{array}{r}\% \text { CSO Vol. } \\
\text { removed by } \\
\text { Existing } \\
\text { Tanks } \\
(\%) \\
\end{array}$ & $\begin{array}{r}\% \text { WWF Vol. } \\
\text { controlled by } \\
\text { Existing Tanks } \\
(\%)\end{array}$ \\
\hline Greenhill & Greenhill & $2,401,000$ & $1,851,500$ & 553,000 & $1,298,500$ & $70 \%$ & $77 \%$ \\
\hline Bayfront Park & Queen \& Hess & 226,000 & 33,900 & 0 & 33,900 & $100 \%$ & $100 \%$ \\
\hline James & James & 52,100 & 12,900 & 1,000 & 11,900 & $92 \%$ & $98 \%$ \\
\hline Main/King & King \& Dundurn & $1,689,000$ & 827,400 & 87,900 & 739,500 & $89 \%$ & $95 \%$ \\
\hline \multirow[t]{4}{*}{ Eastwood Park } & Catharine \& Ferguson & 941,900 & 307,100 & 10,300 & 296,800 & $97 \%$ & $99 \%$ \\
\hline & $\begin{array}{l}\text { Subtotal } \\
\text { (above CSO Outfalls) }\end{array}$ & $5,310,000$ & $3,032,800$ & 652,200 & $2,380,600$ & $78 \%$ & $88 \%$ \\
\hline & All remaining CSO Outfalls & $4,363,400$ & $3,051,400$ & $3,051,400$ & & & \\
\hline & Total (all CSO Outfalls) & $9,673,400$ & $6,084,200$ & $3,703,600$ & $2,380,600$ & $39 \%$ & $62 \%$ \\
\hline
\end{tabular}

Note: $\quad$ Simulations are for the period from April 1 to October 31, 1989 (identified in Polluion Control Plan as the typical year). Rainfall for this period is $459 \mathrm{~mm}$ (from AES Royal Botanical Gardens raingauge). 
occurrence of dry weather overflows, minimize the potential for impacts on human health and aquatic life resulting from CSOs, and achieve as a minimum, compliance with body contact recreational water quality objectives at beaches. This procedure requires municipalities with CSS to develop Pollution Prevention and Control Plans which outline the nature, cause and extent of pollution problems, examine CSO control alternatives and propose remedial measures, and recommend an implementation program including costs and schedules. Procedure F-5-5 requires municipalities to meet seven minimum CSO controls:

1. eliminate CSOs during dry weather periods except under emergency conditions;

2. establish and implement pollution prevention programs that focus on pollutant reduction at source;

3. establish and implement proper operation and regular inspection and maintenance programs;

4. establish and implement a floatables control program to control coarse solids and floatable materials;

5. maximize the use of the collection system for storage of wet weather flows (WWFs) which are conveyed to the WWTP for treatment when capacity is available;

6. maximize the flow to the WWTP for the treatment of WWF; and

7. during a seven month period commencing between April 1-15, capture and treat for an average year all the dry weather flow (DWF) plus $90 \%$ of the volume resulting from WWF that is above the DWF.

The $90 \%$ volumetric control criterion is applied to the flow collected by the CSS immediately above each overflow location unless it can be shown through modeling and on-going monitoring that the criterion is being achieved on a system-wide basis. No increases in CSO volumes above existing levels at each outfall will be allowed except where the increase is due to the elimination of upstream CSO outfalls. During the remainder of the year, at least the same storage and treatment capacity should be maintained for treating WWF. The minimum level of treatment of the controlled CSO volume is primary treatment or equivalent (MOE, 1997). In Hamilton, stored CSOs are conveyed to the Woodward Avenue WWTP where they receive secondary treatment.

The $90 \%$ volumetric control requirement is different from the criteria employed to size the Region's existing CSO storage tanks, which were based upon the ability of the facilities to reduce the frequency and volume of existing CSOs to the levels stated above. The Region's existing CSO tanks were all designed prior to the release of Procedure F-5-5. The Greenhill, Bayfront Park and James Street CSO tanks were sized using a design-storm concept. The Main/King and Eastwood Park CSO tanks were sized based upon twenty years 
of continuous modeling with SWMM. To be sure that these facilities met the new MOE requirements, the Region completed an analysis to compare their performance to the volumetric control requirements of Procedure F-5-5. Table 19.2 shows the performance of the existing tanks against these new criteria, and indicates that all of the facilities, with the exception of the Greenhill Avenue CSO Tank, easily exceed the F-5-5 criteria.

\subsection{Single Event versus Continuous Modeling}

Single event models may be used to evaluate the hydraulic performance of the CSS during specific rainfall events or hypothetical design storms, but the design of CSO abatement facilities such as off-line storage tanks should be conducted by long-term continuous simulation. Reasons include the following:

1. Continuous simulation provides a better accounting of antecedent soil moisture conditions prior to each rainfall event, and thus provides more accurate runoff volumes to be used to estimate CSO volumes, pollutant loads and/or size storage facilities.

2. Design storm analyses assume a given rainfall volume and distribution over time which is rarely (if ever) observed during real rainfall events. The response of a CSS is highly dependent upon the flows that reach its overflow regulators, and as such the shape of the storm event and the resulting flow hydrographs can have a significant impact on the simulated CSO volume and frequency and on the CSO tank volume required to meet volumetric control targets.

3. CSO tanks need to be emptied following wet weather to be fully effective in controlling subsequent events. If a tank is not completely empty prior to a storm, its effective storage capacity is reduced and so is its ability to control a CSO event. Two or more smaller storms can cause a tank to fill and overflow, even if each storm is smaller than the design storm. Conventional design storm methodology does not account for the impacts of multiple events.

4. The time period over which a storage tank is emptied following a storm also impacts the design and performance of these CSO control facilities. Continuous simulation permits accurate simulation of the operation of a CSO tank over time by providing the modeler with the ability to vary and test tank drainage times and rates. 
5. CSO control criteria such as those required by Procedure F-5-5 are based upon the ability of the facility to control a certain volume of CSO over the long-term, not just for a single storm event. The longer the period simulated, the more representative the results will be.

MOE Procedure F-5-5 permits analyses based upon an average year which may refer to the long term average of flow based upon a simulation of at least twenty years of rainfall data, a year in which the rainfall pattern (e.g. intensity, volume and frequency) is consistent with the long term mean of the area, or a year in which the runoff pattern resulting from the rainfall (e.g. intensity, volume and frequency) is consistent with the long term mean of the area (MOE, 1997). The first methodology is preferable because it negates the need to define what constitutes a representative rainfall pattern or resulting flow pattern. Assuming that at least twenty years of historical rainfall are needed to determine which is the average year, and once the hydrologic and hydraulic models are built, it takes little extra effort to simulate the entire period to size the tank based upon the entire flow record. Design storms are still probably the best method to size CSO tank overflow weirs and conduits, provided the design flows they generate equal or exceed the highest flows generated by the continuous simulations.

The temporal resolution of the rainfall is a factor to consider. Rainfall recorded at larger timesteps may tend to underestimate peak flows and to some extent, CSO volumes. However, long-term rainfall records at timesteps smaller than 60 minutes are rarely available. While some inaccuracy may be introduced by the use of rainfall at a 60 -minute timestep, alternatives such as the use of a design storm, or rainfall at a finer timestep for a shorter period of time, or finer timestep rainfall data from another area, are all inferior approaches for the determination of required CSO storage volumes. A finer timestep should be used for the design of overflow channels, control gates and pumps.

\subsection{Methodology for Sizing CSO Storage Tanks}

When the decision was made to build the Main/King and Eastwood Park CSO tanks it was agreed that the tanks should be sized using long-term continuous modeling. The methodology developed for sizing these tanks is illustrated in Figure 19.2. The SWMM models of these catchments were developed from the original SWMM Runoff and Transport model of Hamilton's trunk CSS and outfalls, which was developed for the PCP study (Paul Theil Associates and Beak Consultants, 1991). The original SWMM model included 46 hydrologic basins, 116 conduits, 118 nodes and 44 CSO regulators. In preparing the 


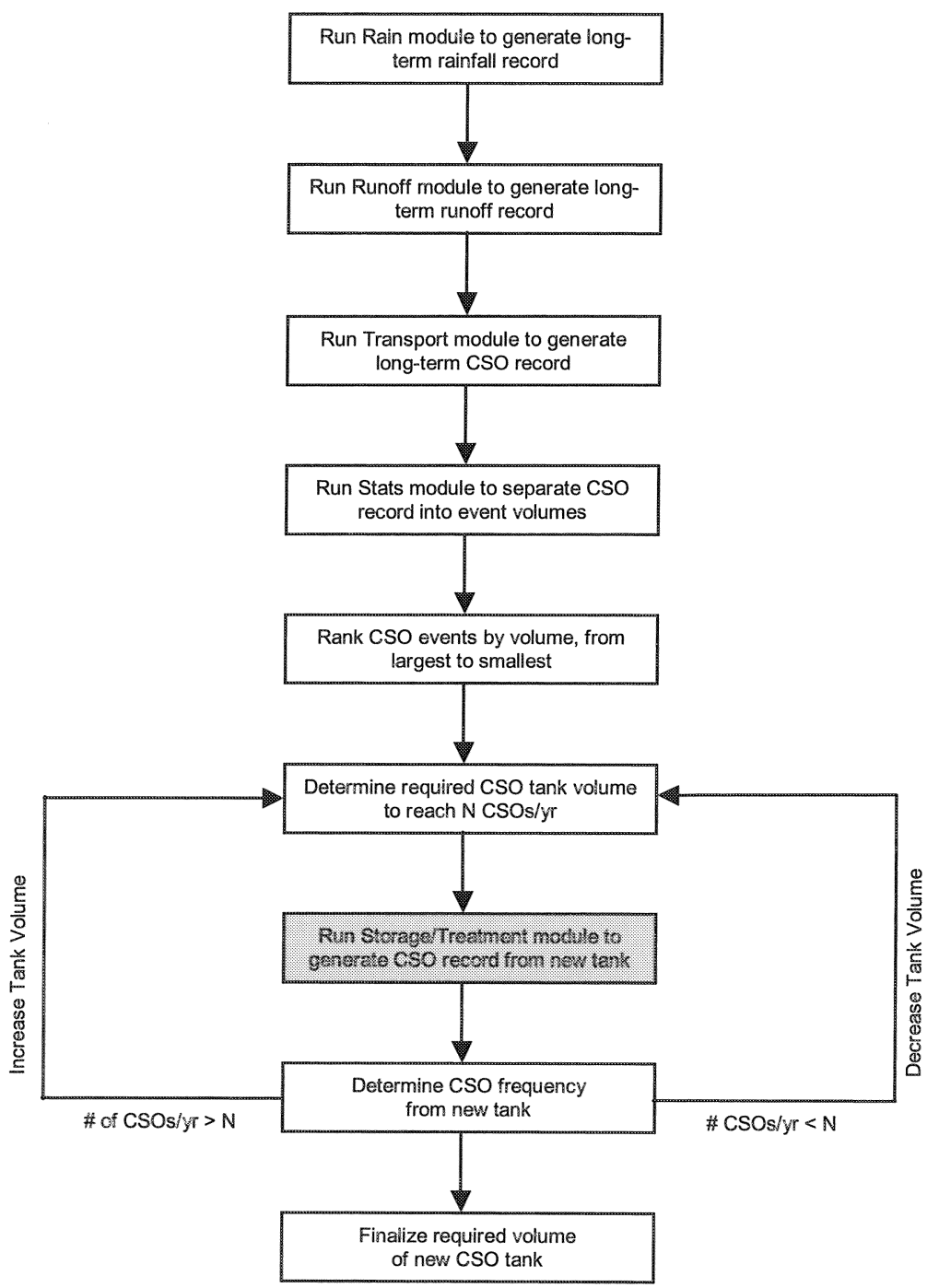

Figure 19.2 Methodology for sizing Main/King and Eastwood Park CSO storage tanks.

original model, a number of CSO regulators were lumped together as single regulators. Following a review of the original Transport model, sewer maps and drawings, a number of the more complex lumped regulator elements were separated and incorporated in an updated Transport model as individual diversion structures. 
Sizing for the Main/King CSO tank was completed entirely by Regional staff. For the Eastwood Park CSO tank, Regional staff prepared the rainfall data and computer models and provided them to a consultant who completed the long-term simulations to determine the required size of the facility. These tanks were designed to reduce the average annual frequency of CSOs at each location to 2-3 times/y (May 1 to October 31). This was based upon the ability of the facilities to meet these criteria as demonstrated by continuous modeling for the 20-y period from 1970-1989.

\subsection{Sizing the New Greenhill CSO Storage Tank}

Construction of the Region's first CSO storage tank, a $70,000 \mathrm{~m}^{3}$ facility located at the east end of Greenhill Avenue, was completed in 1988 prior to the completion of the PCP. The tank is drained by gravity into the Red Hill Creek Sanitary Interceptor (RHCSI) and overflows from the tank are discharged into the Red Hill Creek. This tank was designed to retain the runoff generated by a $15 \mathrm{~mm}$ design storm. Storms of this size occur fairly frequently, and as a result the Greenhill CSO tank typically overflows about 13 times/yr (May 1 to October 31). As shown in Table 19.2, this facility does not meet the CSO control objectives set by MOE Procedure F-5-5. A second Greenhill CSO tank has been proposed to ensure that these control levels are met in the near future. Preliminary design of this facility has already begun and construction is scheduled to be completed by 2003. The remainder of this chapter discusses the methodology used to size the new Greenhill CSO tank.

The main criteria for selecting the size of the new Greenhill CSO storage tank is the $90 \%$ WWF control requirement set by Procedure F-5-5, but there are other design criteria which should be considered. These include the desired frequency of CSO from the new facility and the percent reduction in existing CSO volumes from the outfall. These are often used criteria for designing CSO storage facilities, and were used to size the Region's Bayfront Park, James Street, Main/King and Eastwood Park CSO tanks. There is an additional consideration at the Greenhill CSO outfall. While the four more recently constructed tanks were designed as off-line control facilities, which only receive flow during wet weather, the existing Greenhill CSO tank was designed as an in-line storage facility. The DWF from the contributing CSS passes through the tank continuously, and as part of the improvements at the Greenhill CSO outfall it was proposed to remove this dry weather flow from the existing tank and connect it directly to the RHCSI. The existing Greenhill CSO tank is circular in plan and it is impractical to expand the volume of this facility. It is thus necessary to construct a completely separate new facility to provide the 
additional storage required to satisfy the CSO control criteria identified above. Preliminary engineering work indicates that the new facility is best located upstream of the existing one, and the plan would be to fill the new facility first, then the existing one. Only the overflow from the new facility would be diverted to the existing tank. The wash-down nozzle system used to remove settled solids from the floor of the existing tank is less effective than the sediment flushing tanks employed at the Bayfront Park, Main/King and Eastwood Park CSO tanks and proposed for the new Greenhill CSO tank, and thus the frequency of use of the existing Greenhill CSO tank should be minimized. This became an additional criterion to be considered in sizing the new facility.

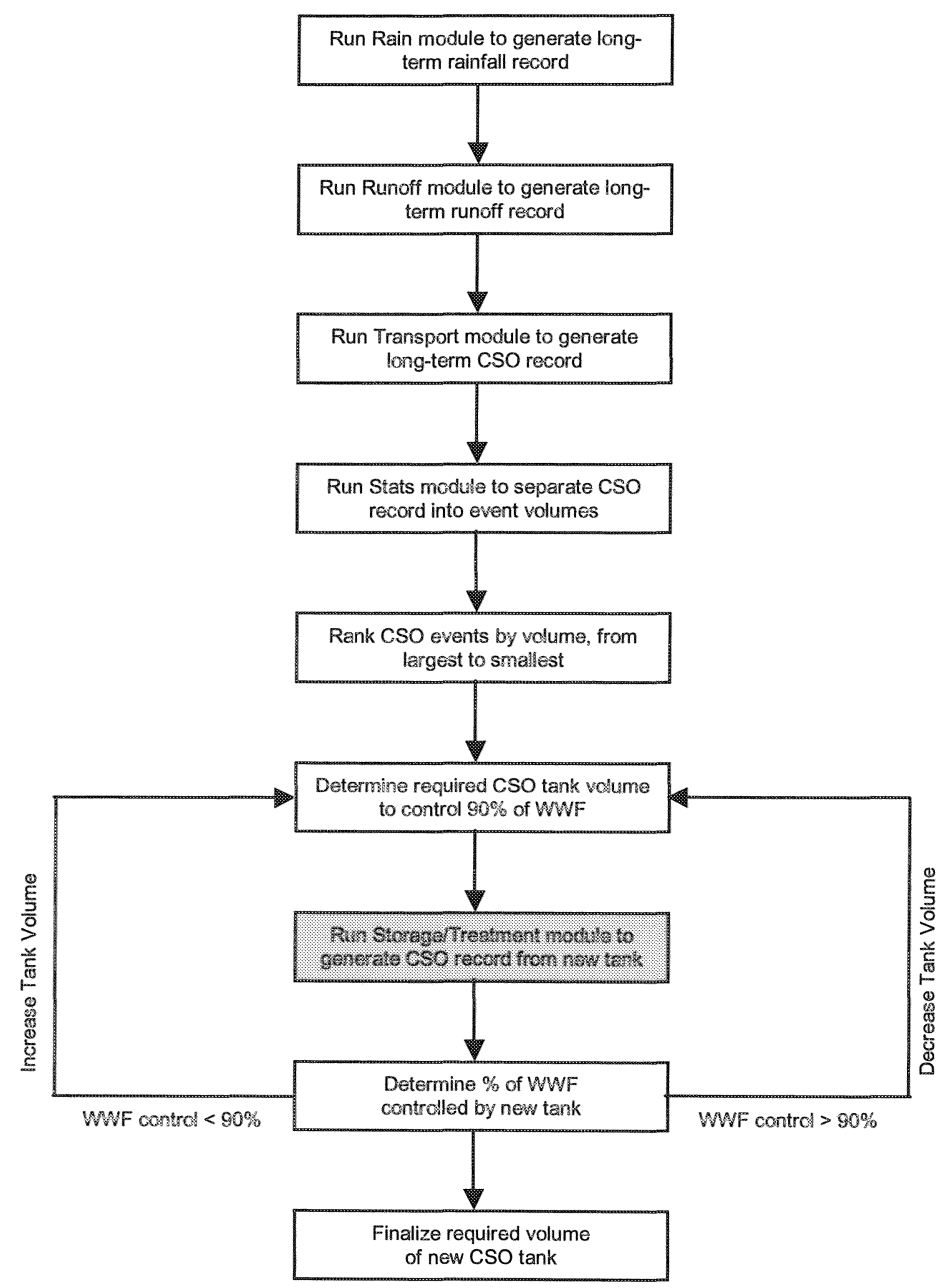

Figure 19.3 Methodology for sizing new Greenhill CSO storage tank. 
Figure 19.3 illustrates the methodology followed to determine the required volume of the new Greenhill Avenue CSO storage tank. This is essentially the same procedure followed in sizing the Main/King and Eastwood Park CSO tanks with two modifications. The simulation period chosen for the continuous simulations was extended to $30 \mathrm{y}$ and CSO frequency was replaced by the $90 \%$ WWF volumetric control requirement of Procedure F-5-5 as the main criteria for sizing the new tank. As mentioned above, CSO frequency, reduction of existing CSO, and frequency of use of the existing Greenhill CSO tank were also considered in selecting the final size for the new facility.

\subsubsection{Rainfall}

The first step in sizing the new tank was to acquire a long-term record of recorded historical rainfall data from within or near the Greenhill CSS. Procedure F-5-5 requires at least 20 y of rainfall. For the sizing of the new Greenhill CSO tank, the 30-y period from 1970 to 1999 was selected. In Hamilton, rainfall data are available from two nearby Environment Canada Atmospheric Environment Services (AES) raingages located at Mount Hope Airport south of Hamilton's CSS and the Royal Botantical Gardens in Burlington, at the west end of Hamilton Harbour. Data are generally available at a 60 -minute timestep from these stations, which have been operating since 1970. The Region also operates a number of raingages in and around Hamilton's CSS. Many of these stations have been operational since 1989, and data are generally available at timesteps as small as 1-minute. Hourly rainfall records from the AES raingages, and 15-minute records from the Region's Mount Hope Airport and Garth Street raingages were processed by the SWMM Rain module for input to the Runoff module. Each year's simulation spanned the period from April 1 to October 31, as specified by Procedure F-5-5.

\subsubsection{Runoff}

The SWMM Runoff model of the Greenhill drainage basin was based upon the original calibrated model developed by the consultant for the PCP (Paul Theil Associates and Beak Consultants, 1991). The hydrologic model of the Greenhill CSS includes eight subcatchments with a total drainage area of approximately 1,260 ha. The Runoff model includes no conduits. All combined sewers and diversion structures are simulated in the SWMM Transport module. Runoff module simulations were completed for the period from 1970-1999. As only the period from April 1 to October 31 was required, each year was simulated separately. SWMM interface files were created for each year for subsequent input to the Transport module. The continuous Runoff simulations also 
provided the total WWF entering the system over the chosen 30-y design period, which was approximately 67.7 million $\mathrm{m}^{3}$. In addition to capturing all DWF, $90 \%$ of this WWF must be controlled to meet Procedure F-5-5. In other words, the CSO volume from the new Greenhill CSO must be less than or equal to $10 \%$ of this WWF volume (i.e. $10 \%$ of 67.7 million $\mathrm{m}^{3}$ ).

\subsubsection{Transport}

Again, the SWMM Transport model of the Greenhill CSS was based upon the original calibrated model developed by the consultant for the PCP. Before using the model again, simulated DWFs were calibrated against recent flow measurements and updated in the model. While the CSS in the older areas of Hamilton (mainly below the Niagara Escarpment) are quite complex and include many diversion structures, the Greenhill CSS includes only one simple diversion structure which is located at the very upstream end of the catchment. This structure has very little impact on the flows conveyed to the Greenhill CSO Outfall, and the new storage tank. The Transport module is sufficient to determine the required size of the new Greenhill CSO storage facility, but Extran should be used in the detailed design of associated overflow channels and control gates. This detailed design will be done by the Region's engineering consultant and is not discussed further in this chapter.

The peaking factor for the Woodward Avenue WWTP is generally accepted to be about 1.5 times its rated capacity of 409 megalitres/d (MLD). For short periods the WWTP can handle in excess of 1.5 times its rated capacity. Thus when we design new CSO tanks, we generally divert 1.5 to 2 times the peak DWF around the tank during wet weather, to be sent directly to the plant for treatment. This reduces the required size of the tank and maintains reasonable inflows at the WWTP during wet weather. The gate setting also ensures that the tanks receive no flow during dry weather. For the Greenhill $\mathrm{CSO}$, we have assumed that up to $1.62 \mathrm{~m}^{3} / \mathrm{sec}$ will be diverted directly to the WWTP. This is the theoretical peak DWF from the Greenhill CSS, and is approximately 1.5 times and 4 times recently measured peak and average DWFs respectively.

SWMM interface files from the Transport module simulations were created for input to the Storage/Treatment and Stats modules. The Stats module was used to separate the events for each of the $30 \mathrm{y}$ into individual CSO events. Normal operation of the CSO tanks entails waiting 12-24 h before beginning to empty them following a storm, and the tanks have typically been designed to permit their drainage from full volume in $24 \mathrm{~h}$. We thus chose an inter-event time of $36 \mathrm{~h}$ to separate the CSO events. The selection of the interevent time in separating the events does not affect the total CSO volume, but 
Table 19.3 Annual CSO event summary from Transport module.

\begin{tabular}{|c|c|c|c|c|}
\hline \multicolumn{5}{|c|}{ Greenhill CSO Event Flow Volumes (1999) } \\
\hline Date & Start Time & $\begin{array}{r}\text { CSO Volume } \\
\left(\mathrm{m}^{3}\right)\end{array}$ & $\begin{array}{r}\text { Duration } \\
(\mathrm{hrs})\end{array}$ & $\begin{array}{r}\text { CSO Volume } \\
\left(\mathrm{m}^{3}\right)\end{array}$ \\
\hline 990403 & 22.17 & 5,305 & 1.33 & 0 \\
\hline 990406 & 14.00 & 5,490 & 1.33 & 0 \\
\hline 990411 & 15.17 & 1,216 & 9.83 & 0 \\
\hline 990422 & 7.67 & 53,750 & 19.17 & 0 \\
\hline 990518 & 17.17 & 31,360 & 6.67 & 0 \\
\hline 990522 & 17.50 & 27,740 & 40.83 & 0 \\
\hline 990601 & 8.83 & 49,830 & 34.17 & 0 \\
\hline 990614 & 11.00 & 18,450 & 3.50 & 0 \\
\hline 990617 & 16.67 & 14,670 & 2.17 & 0 \\
\hline 990627 & 10.00 & 2,279 & 1.17 & 0 \\
\hline 990629 & 4.00 & 12,810 & 1.67 & 0 \\
\hline 990719 & 17.50 & 1,182 & 1.00 & 0 \\
\hline 990724 & 19.83 & 23,320 & 1.83 & 0 \\
\hline 990731 & 15.83 & 184,900 & 3.33 & 114,900 \\
\hline 990807 & 20.33 & 19,060 & 7.33 & 0 \\
\hline 990813 & 22.83 & 10,210 & 1.50 & 0 \\
\hline 990820 & 21.67 & 45,960 & 2.00 & 0 \\
\hline 990826 & 19.50 & 25,880 & 1.83 & 0 \\
\hline 990906 & 21.67 & 40,050 & 2.17 & 0 \\
\hline 990909 & 6.83 & 10,190 & 4.83 & 0 \\
\hline 990913 & 11.50 & 15,600 & 4.67 & 0 \\
\hline 990929 & 10.00 & 176,100 & 15.50 & 106,100 \\
\hline 991003 & 23.50 & 29,150 & 4.50 & 0 \\
\hline 991013 & 15.00 & 134,500 & 10.33 & 64,500 \\
\hline 991017 & 8.50 & 5,116 & 4.83 & 0 \\
\hline 991022 & 10.17 & 7,147 & 1.33 & 0 \\
\hline
\end{tabular}

can impact the number and volume of individual events identified. This was not critical to the design of our new facility to meet the long-term volumetric control criteria of Procedure F-5-5, but is more important when designing storage facilities to meet CSO frequency criteria. The results of the Stats simulations for each year were subsequently imported into a spreadsheet for further analysis. Table 19.3 shows a typical annual CSO event summary generated by the Transport and Stats modules. The last column in Table 19.3 computes the estimated CSO volume from the existing $70,000 \mathrm{~m}^{3}$ Greenhill CSO Tank. This represents the remaining CSO volume which must be controlled by the new CSO tank. As explained earlier, in reality it is proposed to fill the new tank first and send its overflow to the existing tank. The CSO events for the entire 30-y period are then combined and ranked by CSO volume, from largest to smallest. By trial and error or interpolation, a new tank size is selected whereby the amount of CSO from the two tanks (or a single combined tank volume) is less than or equal to $10 \%$ of the total WWF volume entering the CSS which was identified by the 30 -yRunoff simulations (i.e. $10 \%$ of 67.7 million $\mathrm{m}^{3}$ ). 
Table 19.4 Performance of different CSO tanks as determined by Transport module.

\begin{tabular}{lllll}
\hline Tank volume $\left(\mathrm{m}^{3}\right)$ & 132,500 & 65,700 & 43,800 & 16,000 \\
CSO frequency $(\mathrm{CSOs} / \mathrm{yr})$ & 1.0 & 2.0 & 3.0 & 4.0 \\
Remaining CSO volume $\left(\mathrm{m}^{3}\right)$ & $3,175,500$ & $6,111,200$ & $7,678,000$ & $10,521,330$ \\
\% of CSO volume removed & 91.8 & 84.3 & 80.3 & 73.0 \\
\% of WWF controlled & 95.3 & 91.0 & 88.7 & 84.5 \\
\hline \multicolumn{5}{l}{} \\
\hline
\end{tabular}

Table 19.4 summarizes the performance of the existing $70,000 \mathrm{~m}^{3}$ Greenhill CSO tank and presents the results of a sensitivity analysis for various volumes of additional storage provided by the new facility. This is done for a number of different CSO control criteria. This table indicates that $56,000 \mathrm{~m}^{3}$ of new storage needs to be provided to meet the $90 \%$ WWF volumetric control criteria of Procedure F-5-5. It also shows that this much new storage would reduce the number of CSOs at the Greenhill outfall to $2.3 / y$, reduce existing annual CSO volume by $83 \%$, and reduce the frequency of use of the existing Greenhill CSO tank to 7.3 times/y (all April 1 to October 31).

\subsubsection{Storage/Treatment}

The spreadsheet analysis of the Transport module simulations to determine the required storage volume of the tank has a limitation. It does not reflect the operation of the storage tank over time. It basically assumes that the tank is empty at the beginning of each separate storm event identified by the Stats module. In reality, the operation of the tank, specifically when and how quickly it is drained, plays an important role in the level of CSO control it provides. To verify the performance of the tank under expected operating conditions, it should be checked by continous simulation with the SWMM Storage/Treatment module over the same 30-year period. The Storage/Treament module provides two parameters to control the drainage of the tank; when drainage begins following each storm, and the rate of drainage. Two different scenarios can arise: 
1. where the contents of the storage tank cannot be completely drained during the intervening dry period between storm events, the Transport module spreadsheet analysis will underestimate the CSO volume generated because it assumes the tank is empty prior to each storm; and

2. where the Transport module spreadsheet analysis has identified closely following storm events as a single event, but in reality some drainage of the tank did take place place between these events, this analysis will overestimate the $\mathrm{CSO}$ volume generated.

Based upon the Transport module spreadsheet analysis, a total storage volume of $126,000 \mathrm{~m}^{3}\left(70,000 \mathrm{~m}^{3}\right.$ existing $+56,000 \mathrm{~m}^{3}$ new $)$ is required to meet the CSO control criteria set by Procedure F-5-5. Thus, a model of a 126,000 $\mathrm{m}^{3} \mathrm{CSO}$ storage tank was created in the Storage/Treatment module. Operators will generally begin draining the CSO tanks once WWFs to the Woodward WWTP have receded. This typically takes $12-24 \mathrm{~h}$, but has taken longer for very large storms or snowmelt events. Pumps at the existing CSO tanks are typically sized to drain the tanks from full within $24 \mathrm{~h}$. For the purposes of sizing the new Greenhill CSO storage tank, it was assumed that drainage of the tank would not begin until $12 \mathrm{~h}$ following any storm, and the pumps were sized to drain the tank from full in $24 \mathrm{~h}\left(1.46 \mathrm{~m}^{3} / \mathrm{sec}\right)$. The Storage/Treatment module was run for the same 30-y period from 1970-1999, with input provided by the SWMM interface files generated by the Transport module. The results of the simulations are summarized in Table 19.5 . A new $56,000 \mathrm{~m}^{3}$ facility would provide $91 \%$ control of the WWF entering the Greenhill CSS, exceeding the requirements of Procedure F-5-5. It would also reduce the average number of CSOs at the Greenhill outfall from 13/y to 2.6/y and reduce the existing CSO volume by $85 \%$. The continuous DWF entering the existing Greenhill CSO tank would be removed and the tank would be used only 7.3 times/y (April 1 to October 31) on average.

Table 19.5 Performance of new Greenhill CSO storage tank as determined by Storage/Treatment module.

\begin{tabular}{lr}
\hline CSO tank volume $\left(\mathrm{m}^{3}\right)$ & 56,000 \\
Remaining CSO volume $\left(\mathrm{m}^{3}\right)^{1}$ & $5,913,541$ \\
\% of CSO volume removed & 84.8 \\
$\%$ of WWF controlled & 91.3 \\
CSO frequency (CSOs/yr) & 2.6 \\
\hline 't total CSO volume from existing + new Greenhill \\
CSO tanks for 1970-1999 (April 1 to October 31).
\end{tabular}




\subsection{Discussion}

The drawbacks of using the design storm approach to size CSO storage tanks have already been discussed. Table 19.6 compares the required tank volumes to meet different CSO frequency criteria as determined by the design storm and continuous modeling approaches. For the Greenhill CSO tank analysis, the design storm approach underestimates the required storage volume to reach one $\mathrm{CSO} / \mathrm{y}$, but overestimates the volume needed to reach four CSOs/y. This simply means that the one CSO/y Design Storm is undersized and the four CSO/y Design Storm oversized, when compared to the 30-y historical record. The volume differences range from $18,500 \mathrm{~m}^{3}$ to $21,000 \mathrm{~m}^{3}$. The costs of under or over-estimating the storage volume required can be substantial. Our larger facilities have cost approximately $\$ 300 / \mathrm{m}^{3}$ to construct. At this rate, it would cost in the neighborhood of $\$ 6.0$ million to provide this much additional storage. The environmental impacts of underestimating the required CSO storage volume can also be significant. Table 19.6 indicates that a similar volume $\left(21,900 \mathrm{~m}^{3}\right)$ of additional storage would reduce the frequency of CSOs at the Greenhill outfall from three CSOs/y to two CSOs/y (April 1 to October 31 ). It can also mean the difference between meeting and not meeting the requirements of Procedure F-5-5 (89\% versus 91\% control of WWF).

Table 19.6 Comparison of CSO tank sizes determined by design storms and continuous modeling.

\begin{tabular}{lrrrr}
\hline & \multicolumn{5}{c}{ Required CSO tank volume to meet criteria $\left(\mathrm{m}^{3}\right)$} \\
\cline { 2 - 5 } & $1 \mathrm{CSO} / \mathrm{yr}$ & $2 \mathrm{CSO} / \mathrm{yr}$ & $3 \mathrm{CSO} / \mathrm{yr}$ & $4 \mathrm{CSO} / \mathrm{yr}$ \\
Sized by design storm & 114,000 & - & - & 37,000 \\
Sized by continuous modeling & 132,500 & 65,700 & 43,800 & 16,000 \\
\hline
\end{tabular}

\subsection{Summary}

Construction of the Region's first CSO storage tank, a 70,000 $\mathrm{m}^{3}$ facility located at the east end of Greenhill Avenue, was completed in 1988 prior to the completion of the PCP. This tank was designed to retain the runoff generated by a $15 \mathrm{~mm}$ storm, and does not meet new provincial CSO control objectives set out in the MOE's Procedure F-5-5. The Region has therefore decided to construct a second storage tank to improve the level of CSO control at the Greenhill outfall. The sizing of the tank was done in-house by Regional staff using the USEPA SWMM Version 4.0. 
A simple, easy to follow methodology has been developed for sizing the Region's CSO storage tanks, which employs long-term continuous simulation using the USEPA SWMM Rain, Runoff, Transport, Storage/Treatment and Stats modules. Transport module simulation results are employed to develop a fairly accurate estimate of the required storage volume to meet any selected CSO control criteria. In the past, we have sized facilities to meet CSO frequency goals (e.g. 1-3 CSOs/y), but today in Ontario we must control $90 \%$ of the WWF entering our CSS as required by MOE Procedure F-5-5. Many factors can affect the actual performance of such a facility, including contributing rainfall and flow patterns and the mode of operation of the facility itself. The performance of the facility must be verified over long periods of time, and if necessary, the proposed size must be increased to ensure that desired CSO control criteria are met. This can be done using the SWMM Storage/Treatment model. The analysis for the Greenhill CSO outfall determined that a new $56,000 \mathrm{~m}^{3}$ storage tank would meet the Province's requirements for CSO control. We have decided to build a slightly bigger tank at this site to reduce the CSO frequency to less than two CSOs/y and to reduce the usage of the original Greenhill CSO tank to less than once per month. This will require a tank volume of approximately $65,000 \mathrm{~m}^{3}$.

Single event models may be used to evaluate the hydraulic performance of the CSS during specific rainfall events or hypothetical design storms, and to size conveyance elements, but the sizing of CSO abatement facilities such as off-line storage tanks should be conducted by long-term continuous simulation. The costs of under or oversizing CSO storage facilities can be substantial, and it is important to use appropriate and accurate design tools to size such facilities.

\section{References}

Hamilton Harbour RAP Team, 1992. Remedial action plan for Hamilton Harbour goals, options and recommendations: volume 2 - main report. ISBN No. 0-77780533-2.

Ontario Ministry of Environment, 1997. Procedure F-5-5 - Determination of treatment requirements for municipal and private combined and partially separated sewer systems, December 1997.

Paul Theil Associates and Beak Consultants, 1991. Regional Municipality of Hamilton-Wentworth pollution control plan. Prepared for the Regional Municipality of Hamilton-Wentworth, Hamilton, Ontario. 
